\title{
As regras por detrás dojogo: a operação historiográfica de Michel de Certeau na obra de Wlamyra $R$. Albuquerque
}

\author{
The rules behind the game: Michel de Certeau's historiographical \\ operation in Wlamyra R. Albuquerque's work
}

\author{
Rômulo Gonçalves Bittencourt \\ romulo.g.bittencourt@gmail.com \\ Especialista em Direito Constitucional \\ Universidade Federal da Bahia - Campus de São Lázaro \\ Aristides Novis, 197 - Federação (Estrada de São Lázaro) \\ 40210-730 - Salvador - Bahia \\ Brasil
}

\section{Resumo}

O presente artigo se propõe a aplicar a matriz de Michel de Certeau a uma obra historiográfica, $O$ jogo da dissimulação: abolição e cidadania negra no Brasil, de Wlamyra Ribeiro de Albuquerque, de modo a mapear os três elementos componentes da operação historiográfica: lugar social, as práticas e a escrita. Através da análise dos elementos sobre os quais o discurso não fala será demonstrado o nível de participação do historiador no processo de efetivação da pesquisa acadêmica. Desse procedimento resulta a possibilidade de controlar em toda extensão o discurso histórico produzido, ratificando o caráter cientifico do conhecimento histórico, além de promover reflexões atuais sobre questões históricas.

\section{Palavras-chave}

Narrativa historiográfica; Michel de Certeau; Discurso.

\begin{abstract}
This paper proposes to apply Michel de Certeau's matrix to a historiographic work, O jogo da dissimulação: abolição e cidadania negra no Brasil, written by Wlamyra Ribeiro Albuquerque, in such a way as to map the three components of historiographical operation: social place, practices, and writing. Through the analysis of elements which the discourse does not speak of it will be shown the level of participation of the historian in the process of the research realization. From this procedure results the possibility of monitoring in the fullest extent the historical speech produced, ratifying the scientific character of historical knowledge, in addition to promoting current reflection on historical issues.
\end{abstract}

Keywords

Historiographical narrative; Michel de Certeau; Discourse.

Recebido em: 21/10/2016

Aprovado em: 9/3/2016 


\section{O problema da narrativa histórica}

A celeuma em torno da natureza epistemológica do conhecimento histórico, apesar de não tão recente, ${ }^{1}$ ainda se mantém aquecida no âmbito histográfico. Nesse contexto, as problemáticas derivadas das peculiaridades da narrativa histórica podem ultrapassar a dicotomia reinante no campo teórico entre tradução da realidade pretérita e mero elemento textual, sendo a matriz de Michel de Certeau contributiva no sentido de reconhecer a indissociabilidade do aspecto literário ao discurso histórico, porém mitigado por elementos controláveis (OHARA 2013).

A publicação da obra A escrita da História (2015) demonstrou o anseio de Michel de Certeau em estabelecer postulados que apresentassem ferramentas capazes de dissecar o discurso histórico e, a um só tempo, ratificar o caráter científico do fazer historiográfico. Tal caráter, aqui, deve ser compreendido como "um conjunto de regras que permitam 'controlar' operações destinadas à produção de objetos determinados" (CERTEAU 2015 p. 47, nota 5), ou, como disse Chartier (2015, p. 16), ou seja, a História produz discurso científico por se caracterizar como um regime de saber compartilhado.

Mesmo após 30 anos de sua morte, as contribuições de Certeau se mantém hígidas, justamente por não desconsiderarem o caráter singular que o ato de escrever história pressupõe, ou seja, a narrativa histórica seria um processo construtivo e transformador. Não obstante o caráter performativo da produção histórica disfarçado de releitura do passado, ${ }^{2}$ é possível estabelecer balizamentos utilizando os elementos componentes da operação historiográfica (CERTEAU 2015, p. 45-111). Compreender o complexo ato de fazer história como uma operação significa, para Certeau, estabelecer critérios teóricos que delimitem a produção historiográfica. Limites estes, contudo, que não desconsideram o caráter inventivo, transformador e literário do historiador. Sua maior contribuição é não colocar tais questões para debaixo do tapete. Ao revés: escancara as influências externas, denuncia as regras que permeiam o ato de escrita e, sobretudo, revela que a narração, mesmo sendo performática, pode ser controlada.

Orellana (2012, p. 22) defende que os elementos fulcrais da matriz certeauniana seriam a relação subordinativa ao vínculo institucional, o caráter construtivo das fontes e a aproximação de escrita histórica e ficção. Em acréscimo, percebo que todos estes enunciados estão voltados, em especial, ao discurso do historiador, expresso no texto escrito. Seguindo a lógica de Voigt (2014), a discussão central de Certeau está voltada para a escrita, aqui encarada pelo seu viés narrativo, embora esta análise pressuponha o estudo prévio do lugar

\footnotetext{
${ }_{1}^{1}$ Uma das possíveis reflexões sobre o status cientifico da História se concentra no debate sobre o caráter da narrativa histórica. De Leopold Van Ranke a François Dosse, passando por Robin George Collingwood, Paul Veyne e Roger Chartier, até o debate entre Carlo Ginzburg e Hayden White, a teoria da história ainda se encontra envolvida pela necessidade de compreensão da natureza mesma do conhecimento histórico.

2 Nesse ponto me afasto da concepção de Durval Albuquerque Jr. (2009a), que identifica a operação historiográfica de Michel de Certeau como um caráter maquínico, haja vista o referido historiador não rejeitar o aspecto criativo no processo de produção textual - apenas defende, em síntese, que o discurso histórico, apesar de performático, não é aleatório, já que se articula com o lugar social do historiador e as técnicas metódicas (VOIGT 2014).
} 
social e da forma procedimental com que o historiador lida com as fontes e com a própria História, isto é, as práticas.

Mesmo partindo dessas premissas, nada faz sentido caso não seja visualizado o historiador como aspecto central de todo este processo. Afinal, é o seu agir que otimizará a articulação dos três componentes sobre os quais o discurso não fala. Encarado o problema dessa forma, percebo que o olhar sobre os fundamentos do conhecimento histórico não se dissocia da prática histórica. A relação simbiótica entre teoria e base empírica contempla, assim, uma análise conjunta.

\section{Os postulados de uma ciência histórica: a matriz certeautiana}

As preocupações lançadas por Michel de Certeau no capítulo $A$ operação historiográfica se lastreiam na tentativa de compreensão da natureza central do complexo processo de elaboração de um texto com conteúdo voltado para o passado. ${ }^{3}$ Em outras palavras, pretende o referido autor fazer emergir a engrenagem que compõe o ofício do historiador. O produto histórico seria-a reunião de um lugar social, de procedimentos práticos analíticos e de uma construção textual, postulados sobre os quais, como dito, o discurso não fala (CERTEAU 2015, p. 46). Porém, mesmo silencioso, o discurso produzido não deixa escapar os limites, funções e escopo do ato de escrever história. Haveria, assim, um tripé silencioso que sustentaria toda operação histórica.

Nesse cenário, o local institucional em que está imerso o historiador oferece instrumentos e condicionantes para o estudo sobre o passado. Este aspecto, 80 para Certeau, apesar de não dito, integra as decisões do historiador, seja na elaboração da pesquisa, seja na própria escrita. Já os procedimentos técnicos que vão nortear a pesquisa acadêmica ultrapassam a simples escolha metodológica. Certeau encara essa fase como uma criação instrumental do historiador, que propiciará, por meio do arcabouço material, subsídios para a narrativa, além de contemplar a própria identidade do pesquisador às funcionalidades da História. Por fim, o texto será fruto da capacidade do historiador em transitar pelas especificidades que a narrativa histórica pressupõe, conferindo-Ihe credibilidade e inteligibilidade, tornando-se, assim, discurso.

Apesar desses componentes se encontrarem diluídos nos textos historiográficos, apresento como proposta deste artigo tornar visível tal universo submerso. Proponho, assim, mapear os pressupostos teóricos ventilados por Michel de Certeau em uma obra historiográfica específica. Por meio desse procedimento, será possível identificar o grau e a intensidade do historiador na construção do conhecimento histórico, que permeia todo o caminho da pesquisa e, até muitas vezes, antes dela. Compreendendo essa unidade divisível, pretendo utilizar o livro $O$ jogo da dissimulação: abolição e cidadania negra no Brasil, de Wlamyra Ribeiro de Albuquerque (2009), para demonstrar a viabilidade e pertinência das propostas de Certeau em sua operação historiográfica, cujo conteúdo remete ao esforço de legitimação do próprio produto histórico. ${ }^{4}$

\footnotetext{
${ }^{3}$ A partir deste ponto, ao referir-me a Michel de Certeau, estarei mencionando Certeau (2015).

${ }^{4} \mathrm{Em}$ momento algum no texto afirmo ter Albuquerque utilizado a operação historiográfica de Certeau como referencial teórico; reconheço, como será melhor apontado adiante, que a análise da autora está sustentada
} 
A obra a ser analisada remete à tese de doutorado da historiadora Wlamyra Ribeiro de Albuquerque, que se propõe a analisar a conformação dos novos contornos sociais no período final do século XIX no Brasil pelo viés de que a racialização das relações foi forjada por diversos setores, num complexo jogo de disputas de espaço, sobretudo após a abolição da escravatura. A escolha se deve a dois fatores: (i) trata-se de uma obra que amplia as discussões sobre a condição dos ex-escravos no período pós-emancipacionista, relativizando o limiar entre escravidão e trabalhadores livres sob o viés cultural (racialização das relações sociais) e (ii) por inovar, no âmbito historiográfico, o aspecto da constituição racial como modulador da sociedade brasileira no final do século XIX, de modo a historicizá-lo. ${ }^{5}$

\section{O pertencimento da autora}

Elemento precedente da pesquisa, o ambiente que norteia a historiadora serve como vestígio das decisões que marcam a sua vida acadêmica. Entretanto, para além de um possível determinismo acadêmico, não se pode desconsiderar o que atravessa e o que é atravessado no ato da pesquisa e na escrita.

A trajetória pessoal de Wlamyra Albuquerque deixa transparecer o fato de haver uma relação necessária entre escolhas, identidades e vínculo institucional. ${ }^{6}$ Afinal, ainda que inicialmente não tenha vislumbrado as possibilidades que o conhecimento histórico iria lhe proporcionar, a estudante recém-formada em um contexto tão opressor e ao mesmo tempo tão fascinante como o da cidade de Salvador percebeu desde logo que suas inquietações mereciam uma reflexão aprofundada: "ter saído da periferia e circulado em espaços absolutamente improváveis, que jamais pensaria ter um dia transitado ou ocupado, isso definiu o meu lugar como pesquisadora, os meus interesses de estudo" (ALBUQUERQUE 2016).

Esse caminhar não-linear, portanto, é permeado de subjetividade e de percalços. O debruçar sobre estudos da historiografia escravista foi, assim, uma escolha transindividual, por aliar um desejo e uma demanda social. Dentro dessa ausência de um sentido lógico, mesmo após a conclusão de sua dissertação, defendida em 1997 no Programa de Pós-Graduação em História da Universidade Federal da Bahia, intitulada O civismo festivo dos baianos: comemorações da independência na Bahia (1889-1923), Albuquerque ainda não havia sintetizado e reverberado suas inquietações. Nesse trabalho, especificamente, propôs uma reconstrução da pluralidade de significados políticos que os festejos da independência da Bahia, comemorada no 2 de julho, assumem no final do século XIX (KRAAY 2001/2002, p. 255).

na História Social da Cultura, "a qual tem em Thompson e Geertz as principais referências", como indicada por um dos pareceristas anônimos deste artigo.

${ }^{5}$ Walmyra Albuquerque, em réplica à resenha produzida sobre sua obra, elencou três outros trabalhos que circunscrevem o tema racial no período emancipacionista brasileiro (cf. ALBUQUERQUE 2011).

${ }^{6}$ Parte das informações que compõem a seção 2 e parcialmente a seção 4 deste artigo foi obtida a partir de entrevista concedida por Wlamyra Albuquerque ao autor em 7 de outubro de 2016, nas dependências da Biblioteca Reitor Macedo Costa, no Campus Ondina da Universidade Federal da Bahia. 
Talvez o próprio lugar de produção acadêmica, o Programa de Pós-Graduação em História da Universidade Federal da Bahia, não estivesse permitindo maiores desdobramentos em sua pesquisa. O não dito que denuncia Certeau é latente: procurar novos desafios poderiam lhe proporcionar um novo olhar, a mensurar anseios e propósitos:

[...] [n]ão é só talento que faz acontecer, o que faz são as oportunidades e os deslocamentos. A gente cresce quando se desloca. O modo como produz ciência está diretamente relacionado com as escolhas e a forma como lidamos com a vida. Quanto mais você se coloca no que Ihe é confortável menos chance se terá de produzir algo original. [...] O deslocamento, o estranhamento de situações e locais diferentes, o desafio da alteridade, de se colocar no lugar do outro e da empatia (e se dando conta das diferenças), é estruturante para uma historiadora. A gente sofre, mas passa. O importante é encarar isso como desafio (ALBUQUERQUE 2016).

Ainda dentro dos estudos sobre a escravidão, Wlamyra Albuquerque ingressou na linha de pesquisa de História Social da Cultura da Universidade Estadual de Campinas. Preciso, nesse ponto, registrar que os dois Programas de Pós-Graduação possuem uma conexão entre si. Segundo Albuquerque (2016), a experiência vivida entre as duas instituições mostrou a forte identidade de temas, objetos de estudo e formas narrativas entre elas. Em sua perspectiva, essa aproximação se deve, em especial, pela intermediação do historiador João José Reis, ${ }^{7}$ que teria fomentado esse diálogo acadêmico.

Retomando ao momento de acesso aos estudos prévios à realização de sua tese, Albuquerque, ao se deparar num ambiente de hegemonia branca, se insere na discussão sobre a implantação de cotas em universidades públicas, em pauta nos idos de 2002. Numa sociedade marcada pela desigualdade, se propõe a historicizar o conceito de raça, de modo a buscar compreender o processo em que se deu, no período do Brasil emancipacionista, a conformação e os arranjos sociais pautados em critérios raciais (ALBUQUERQUE 2016). Considero que o cenário vigente foi provocativo e instigou a autora a qualificar o tema racial para o âmbito de sua pesquisa. Os problemas hodiernos resultantes da constituição da raça como parâmetro social parecem ter estimulado Albuquerque a estudar e compreender a própria historicidade deste conceito tão caro à sociedade brasileira.

Essa inquietação pode ser traduzida como os interesses, aspecto estabelecido por Jörn Rüsen (2001, p. 164) como inicial na produção historiográfica, isto é, "carências de orientação humana na vida prática, decorrentes das experiências da contingência da evolução temporal do mundo humano". Em suma, os

\footnotetext{
7 Joao José Reis é historiador que dispensa apresentações. Ainda assim, reproduzo as palavras Durval Muniz Albuquerque Jr. (2009b, p. 211) que sintetizou o lugar por ele ocupado entre historiadores de prestigio: "João José Reis é merecidamente um figurão da historiografia brasileira. Seus livros, desde o pioneiro Rebelião escrava no Brasil, modificaram o estado da arte dos estudos sobre escravidão, sobre rebelião escrava e movimentos sociais, não só no país, mas internacionalmente".
} 
interesses são provocados e estimulados por carências de orientação de temas presentes. ${ }^{8}$ Ora, o passado necessita ser revisitado diante das demandas sociais da atualidade, influenciando, pois, novas abordagens de estudos. Por essa razão, inclusive, "uma situação social muda ao mesmo tempo o modo de trabalhar e o tipo de discurso" (CERTEAU 2015, p. 59).

Preciso, porém, pontuar que o objeto de pesquisa de Albuquerque sobre os períodos pré e pós-abolicionistas somente se fez possível diante do amadurecimento das discussões sobre a própria historiografia da escravidão, ${ }^{9}$ a qual se renovou no final da década de 1980 e notadamente se alargou pela ampliação dos Programas de Pós-Graduação em História no país durante os anos 1990 e 2000.10 Assim, vejo o que permite e o que proíbe propostos por Certeau como elementos mitigadores da liberdade individual da historiadora: a pesquisa (e, por extensão, a escrita) não é um ato livre, porque o lugar social abre possibilidades de estudo e fecha outras. O edifício historiográfico sobre a escravidão diversificou fontes, métodos e avanços sobre a complexidade envolvendo a sociedade brasileira, ultrapassando a visão binária e maniqueísta de escravos e senhores. ${ }^{11}$ Schwartz (2001, p. 24-29) esclarece que o centenário da abolição, em 1988, intensificou os estudos anteriores sobre a escravidão e deu novo fôlego a dois eixos centrais ao tema: a escola de São Paulo e Frank Tannenbaum. Logo, as novas produções acadêmicas, nas quais se insere a obra de Albuquerque, se encontram vinculadas a este caminho historiográfico.

A instituição histórica (CERTEAU 2015, p. 51-57), como universo doutrinário (ora exemplificada pelas Universidades e Instituições de pesquisa) se retroalimenta das produções historiográficas. Entretanto, chamo atenção ao fato de que as produções acadêmicas resultam de tensões criadas pela própria academia. Ora, o discurso histórico é destinado sobretudo a este progresso historiográfico, o qual não se faz senão com embates. A instituição histórica (in)valida a produção textual realizada pelos historiadores: não é à toa que a obra de Albuquerque aqui analisada tenha sido objeto de diversas resenhas. ${ }^{12}$ A recepção pelos "seus pares" a que menciona Certeau (2015, p. 57) é um rito indispensável para incorporação de um estudo ao universo historiográfico.

A propósito, Lima (2009), em resenha ao livro de Albuquerque, menciona que a obra não teria alcançado a contento seu principal propósito de revelar as estratégias esquemáticas de utilização da raça como critério de hierarquização social. Em suas palavras, "Wlamyra tende a ler os conflitos sociais que encontra

\footnotetext{
8 Para melhor visualização do elemento interesses proposto por Rüsen (2001) em uma obra historiográfica, ver Pereira (2007).

9 Para melhor visualização deste caminhar sobre os estudos de temas envolvendo escravidão vide o balanço historiográfico em Schwartz (2001).

10 Embora Carlo Fico e Ronald Polito (1992, p. 33) afirmem que a criação dos programas de PósGraduação tenha se iniciado no Brasil na década de 70, foi no período de 80-89 que tais institutos se consolidaram. Esse processo de expansão novamente se intensificou, passando de 16 Universidades a oferecer cursos de especialização para os atuais 110, conforme estatística da CAPES. Disponível em: https://sucupira.capes.gov.br/sucupira/public/consultas/coleta/programa/quantitativos/quantitativoIes. jsf ?areaAvaliacao $=40 \&$ areaConhecimento $=70500002$.

${ }_{11}$ Como indicado por um dos pareceristas anônimos deste trabalho, essa renovação se deve em especial à utilização do referencial teórico-metodológico da escola marxista britânica, sobretudo de Thompson, adotando uma história "vista de baixo".

12 Nesse sentido, ver Lima (2009), Brito (2011), Cowling (2011), Domingues (2011) e Gomes (2011).
} 
majoritariamente como conflitos 'raciais', promovendo a simplificação do quadro de antagonismos, negociações, indignações, identificações" (LIMA 2009, p. 252).

Em réplica, Albuquerque (2011) rebate o suposto insucesso da hipótese, retomando questões nela fixadas para demonstrar que o jogo social que pautou a sociedade brasileira pós-abolicionista não se resumiu a uma relação cartesiana binária. Segundo ela, "[n]o período que investiguei, a população negra também forjou identidades a partir de um discurso racial. É o que evidencio no último capítulo do livro sobre clubes carnavalescos repletos de gente de cor, brasileira, que, publicamente, se dizia africana" (ALBUQUERQUE 2011, p. 292).

A autora ainda pontua a necessidade de reflexão do tema proposto, numa clara defesa argumentativa sobre as criticas direcionadas por Lima (2009):

[...] [p]or fim, o resenhista supõe ter descoberto a intenção por trás do argumento do livro: sensibilizar politicamente os leitores 'em relação à denúncia ao racismo'. Ora, denunciar o racismo num país onde ainda se teme enfrentá-lo não é tarefa menor, mas em $O$ jogo da dissimulação pretendo e realizo um tanto mais. Por isso, com a simplicidade que me cabe, convido os leitores a lê-lo e tirar as suas próprias conclusões (ALBUQUERQUE 2011, p. 296).

Acaso as leis do meio (CERTEAU 2015, p. 57) fossem desimportantes, tal debate não ocorreria. Mas, pelo contrário, ele é mais um elemento constituidor da própria produção historiográfica. Seguindo as linhas de intelecção de Certeau, ouso afirmar que a pesquisa tem como destinatários diretos a sociedade e o próprio cenário acadêmico, afinal as produções históricas ultrapassam o interesse acadêmico, possuindo também a repercussão das obras junto ao público em geral (FICO; POLITO 1992, p. 141).

Dessa forma, o mercado editorial apesar de estimular esse nicho, também estabelece critérios de modo a tornar obras produzidas com regras da academia acessíveis a este público. Nesse sentido, a obra de Albuquerque, por tratar de uma experiência ainda persistente em nossa sociedade e utilizar variadas fontes, inclusive literárias e poéticas, mostra as possibilidades de tornar mais atraente tal tema ao universo não acadêmico, sem perda das características essenciais de produção do conhecimento histórico.

A produção historiográfica é, portanto, muito mais um conjunto de interferências do meio (seja ele individual, social ou institucional) do que um resultado abstrato extraído do passado. Sendo assim, o jogo da dissimulação a que alude Albuquerque serve também para compreender as produções acadêmicas, resultado do cruzamento de reservas de domínio: institucional, individual e social, num verdadeiro palco de conflitos e tensões não declarados. As provocações de Michel de Certeau ainda possuem um caráter denunciante.

\section{Para além do tecnicismo}

A realização da pesquisa acadêmica ultrapassa a instrumentalização metódica e requer, conforme defende Certeau, uma atuação do agente-historiador, que não só medeia o processo de seleção documental como também age na 
elaboração de um contexto histórico a subsidiar a futura narrativa. Entretanto, o sujeito articulador desse processo não é essencialmente livre: existem balizas. Nesse sentido, "o lugar que se dá [o historiador] à técnica coloca a história do lado da literatura ou da ciência" (CERTEAU 2015, p. 65).

O cerne da discussão lançada por Albuquerque na obra em análise é desvelar o processo de racialização das relações sociais durante o período entre a emancipação do Brasil e o fim da escravidão, isto é, demonstrar os caminhos de elaboração de discursos raciais como critério de hierarquização e moldura da sociedade baiana no final do século XIX. O jogo da dissimulação: abolição e cidadania negra no Brasil trata de três episódios que constituem o núcleo duro da narrativa, os quais não se encontram intrinsecamente interligados: o incidente diplomático envolvendo Inglaterra e Brasil acerca do desembarque de dezesseis africanos em 1877 no porto de Salvador; o caso intitulado o massacre do Taboão e as representações do desfile do clube Embaixada Africana e dos Pândegos d'África no carnaval de 1897 na cidade de Salvador.

Como então atribuir uma conexão a estes episódios dentro do escopo almejado? A autora dá a pista: "tentei elaborar um texto como quem monta um mosaico, recompondo informações e buscando organizá-las de modo a construir imagens de uma sociedade imersa em uma crise e, portanto, marcada por conflitos e contradições" (ALBUQUERQUE 2009, p. 43). Desse excerto, percebe-se o caráter transformador da pesquisa, que não se limita a extrair dos vestígios um sentido, mas sim um discurso, naquilo que Certeau nomeia de articulação natureza-cultura. Logo, o historiador interage no processo de seleção, de corte e descarte documental para ressignificar as abordagens que as fontes individualmente indicam e/ou sugerem.

$\mathrm{Na}$ primeira parte do primeiro capítulo, intitulado "Cônsules, doutores e os 'súditos de cor preta': razões e ações políticas num processo de racialização", a estruturação das fontes se encontra sustentada pelo itinerário processual do caso envolvendo os já mencionados africanos viajantes. A articulação consciente da historiadora em torno dos precedentes do Conselho de Estado sobre casos supostamente análogos e a trajetória individual de cada um dos seus integrantes - Nabuco de Araújo, Visconde de Jequitinhonha e Eusébio de Queiroz - tem o propósito de demonstrar "que os juristas do Conselho de Estado não pretendiam explicitar nenhum critério racial para justificar suas decisões" (ALBUQUERQUE 2009, p. 73). Nesse capítulo, ainda, há menção à heterogeneidade do movimento abolicionista, como demonstram os exemplos de Manoel Querino e Rui Barbosa, os quais possuíam visões identitárias distintas: raças emancipadoras e emancipadas.

O capítulo seguinte, intitulado "'Não há mais escravos, os tempos são outros': abolição e hierarquias raciais no Brasil", trata sobretudo de fontes policiais para narrar o contexto em que se via a sociedade após o advento da lei no 3.353, de 13 de maio de 1888 - a Lei Áurea. Nesse ponto, a própria historiadora demonstra sua atitude proativa na delimitação documental, considerando seu escopo central de evidenciar de que forma a sociedade pósabolição se apercebia, considerando, claro, as questões raciais: 
[...] [d]iante desse tabuleiro de infindáveis possibilidades preferi me concentrar no que de fato interessava para o argumento do livro, quer seja, se eram consideradas plausíveis as queixas e inseguranças das autoridades policiais e administrativas. Isso quer dizer que não parti para apurar até que ponto todas as denúncias de desordens provocadas pelos "emancipados" tinham fundamento. Tampouco contabilizei quantos homens e mulheres de cor - trezes de maio ou não - atentaram contra a vida dos seus ex-senhores - brancos ou não. O fundamento que importava para minha tese era o da legitimidade daquele discurso que creditava qualquer exaltação popular ao fim da escravidão, ao desmantelo da ordem sustentada nas relações de subalternidade dadas pelas condições de escravo e senhor (ALBUQUERQUE 2011, p. 291).

Já no terceiro capítulo, "Divergências políticas, diferenças raciais: Rui Barbosa e Guarda Negra", a historiadora enxerta significados de um documento apócrifo que descreve o episódio da vinda do republicano Silva Jardim a Salvador em 1889. A carta anônima a Rui Barbosa é integrada por outras fontes, tais como as memórias de Silva Jardim e Rui Barbosa, além de jornais da época. 0 conjunto dessa coleção remonta o episódio denominado o massacre do Taboão e conduz à ideia lançada por Albuquerque de que os antagonismos partidários foram forjados por critérios racializantes, embora deixe evidenciado que a separação entre brancos e negros não consegue traduzir a complexidade dos diversos posicionamentos políticos da época.

O último capítulo da obra, "Esperanças de boas venturas: as Áfricas recriadas na Bahia", também serve como demonstração da interferência da historiadora nas escolhas e recortes documentais. Após trazer elementos em torno de agremiações carnavalescas negras em Salvador e seus desfiles no final do século XIX, Albuquerque nos apresenta os estudos de Nina Rodrigues e Manoel Querino e, ao entrecruzar tais fontes, argumenta que ambos possuíam representações distintas sobre a apropriação das heranças africanas e tradução da cidadania negra por parte das referidas escolas de carnaval (ALUBQUERQUE 2009, p. 224).

Exemplos como estes reforçam a noção de envolvimento do historiador nas escolhas de documentos aparentemente díspares e não intrinsecamente vinculados de modo a reuni-los e, em seguida, conferir-Ihes uma inteligibilidade na narrativa. O historiador transforma os vestígios em objetos de valor. Embora os relatos em si mesmos não apresentassem explicitamente qualquer menção ao forjamento de identidades raciais, é a historiadora que propõe este enfoque, e, a partir dessa hipótese, sugere uma forma poiética de ressignificação das fontes, mas dentro do limite material destes vestígios.

Como já mencionado anteriormente, a contribuição de cada estudo sobre o passado representa um avanço argumentativo num conjunto historiográfico precedente, um verdadeiro desvio de modelo proposto por Certeau (2015, p. 77), em que o historiador não busca mais levantar questões totalizantes, mas pontuar a construção historiográfica que lhe é anterior, visando a novas direções a esta edificação. A busca pela síntese, outrora o ápice de uma pesquisa, é, atualmente, o seu ponto de partida. Por essa razão, os atuais estudos são voltados para questões marginais porque partem da totalidade para inseri-los. 
A própria estrutura do trabalho em análise, exposto em três grandes eventos, não possui uma associação explicita entre si. Não foram os documentos por si mesmos, portanto, que nortearam a historiadora; foi ela que priorizou determinadas fontes (jornais, livros, documentos oficiais, poesias) para, nessa extensão, constituir um corpus que lhe permitisse discutir o processo de conformação da sociedade pela racialização das relações sociais. E, ao apresentar esta nova categoria sociológica, Albuquerque entra em diálogo direto com historiadores americanistas que analisam a questão da raça como elemento central da estrutura social dos Estados Unidos. Sua obra, portanto, é mais um passo diante das reflexões estabelecidas por Robert Miles, Rebeca Scott e Barbara Fields sobre a questão racial, tendo como enfoque sua historicização no Brasil do final do século XIX (ALBURQUERQUE 2009, p. 35).

A prática historiográfica, contudo, não se limita à atividade de redistribuição e ressignificação das fontes, nem de contribuição pontual. Conforme alerta Certeau $(2015$, p. 85$)$, as mudanças funcionais da História promoveriam novas formas de compreender o processo de conhecimento histórico. A construção de identidades e, em consequência, de categoriais sociais pelo manuseio do discurso racial representa a personificação da própria linha de pesquisa na qual a historiadora esteve inserida (História Social da Cultura) durante a pesquisa que resultou na tese ora em discussão. ${ }^{13}$ Logo, faz todo sentido a proposição da autora de analisar o desenvolvimento de enquadramentos e funções de diversos atores sociais pelo viés da racialização dentro do campo de pesquisa desenvolvido pela Unicamp. E, ao assim fazê-lo, realiza uma reelaboração, no âmbito historiográfico, do conceito cultural e antropológico de raça, o que denota - embora não haja menção expressa nesse sentido - a função da História do trabalho sobre o limite, de modo a torná-la verdadeira instância reflexiva e validadora de categorias de outras ciências.

Todas estas questões associadas à pesquisa refletem, também, na necessidade de criação de novos pressupostos e/ou postulados ao conhecimento histórico (CERTEAU 2015, p. 85-89). Compreendo que a mudança da visão teleológica tradicional para uma visão negativa desloca o sentido e a direção da História. A construção outrora de um dever-ser é alterada para um desvio de sentido, de caráter negativo, não necessariamente vocacionado a uma única orientação. Com efeito, Sousa (2011, p. 186) alerta que o enaltecimento a objetos de estudo particulares não exclui a necessária conexão com as questões gerais estruturantes.

A proposta de Albuquerque de analisar o processo histórico de constituição da raça em toda sua complexidade na cidade de Salvador no final do século XIX, ultrapassando a visão dicotômica birracial, traduz essa nova função da História, que se opõe a um caráter finalístico e generalizante: "[a]ssim, o que me interessou foi como aquela sociedade convulsionada por graves mudanças

\footnotetext{
13 Essa linha de pesquisa é integrante da área História Social. Em apertada síntese, a História Social da Cultura analisa as questões derivadas da sociedade dentro de uma perspectiva cultural dos seus atores. Para maiores esclarecimentos, ver o sítio da Unicamp: http://www.ifch.unicamp.br/ifch/pos/historia/0/296/ linhas-pesquisa.
} 
políticas e culturais preencheu o conceito de raça com significados próprios, trazidos à baila em diferentes ocasiões" (ALBUQUERQUE 2011, p. 292). O acervo documental em si mesmo apenas oferece a fluência dos eventos. Ao historiador caberia estabelecer induções dos casos singulares ao contexto que o cerca, tornando esse itinerário ponte para experimentação de novos limites sobre as produções historiográficas pretéritas (CERTEAU 2015, p. 87).

A obra de Albuquerque é repleta de exemplos de possibilidades de expansão dos acontecimentos. A narrativa sobre o não desembarque de africanos no porto de Salvador em 1877 serviu para justificar sua hipótese de que havia um discurso velado e discriminatório pelo Estado brasileiro, isto é, "avaliar em que medida estavam em curso políticas públicas fundadas em critérios raciais" e "como evitar que pessoas de cor imigrassem para o Brasil sem lançar mão de uma legislação racista?" (ALBUQUERQUE 2009, p. 38 e p. 66, respectivamente). Diante do desfecho tomado pelo Conselho de Estado em não permitir o desembarque dos dezesseis africanos comerciantes, a historiadora levanta uma série de outras problematizações subjacentes ao escopo de sua tese central: a existência de um circuito transatlântico comercial e cultural entre a África e o Brasil, o interesse mercantil da Inglaterra no desenvolvimento desta circulação e a omissão velada e deliberada de manutenção da precariedade da liberdade dos negros.

Se existe interferência direta do historiador sobre o acervo documental, e considerando que as novas peculiaridades do conhecimento histórico acima ventiladas também interferem neste processo de pesquisa, Certeau extrai de todas estas questões pressupostas que o caráter ambivalente do passado e do futuro irá nortear toda a extensão da prática historiográfica. Haveria, assim um caráter dúplice da História, porquanto a prática não só atualiza o passado como também oferece respostas a um futuro, embora o modo como essas assertivas serão mensuradas depende do caráter conservador ou utópico do historiador (CERTEAU 2015, p. 86). Dito de outra forma, a pesquisa histórica pressupõe a presentificação do passado, atualizando as carências de um futuro possível. Essa característica de inserção do passado pelo historiador, que se convertem em expectativas, dará o tom da pesquisa e, por conseguinte, da narrativa.

Nesse ponto, não se pode desconsiderar a questão racial como um legado de experiência traumática em nossa sociedade. Não por acaso, a perspectiva de ruptura de Albuquerque (2016) revela a forma como operacionalizou sua pesquisa sobre a construção da noção de raça em nosso país:

[...] [a] questão da identidade é uma demanda derivada de uma sociedade muito racializada, onde o racismo ainda pauta a vida cotidiana. Será incrível quando negros, indígenas, discutirem questões totalmente diferentes deles, como astrofísica. De que forma isso irá impactar um historiador negro que não discute raça? [...] Isso ainda não é possível porque a questão racial ainda é muito dolorida, ainda é uma ferida aberta. Por isso que todos que participam entram nessa discussão, mas eu tenho a esperança de que haverá um tempo em que você não precise dizer: aquele historiador negro [...]. Nisso tem uma utopia de buscar um mundo melhor para todos, mas acho isso possível. Por isso o desejo, utópico, é que isso [a questão racial] pouco importe (ALBURQUEQUE 2016). 
A percepção do ambiente que a cerca serve de mola propulsora no seu espectro de atuação como pesquisadora. Os recortes temporais (período emancipacionistas e pós-abolição), a formulação de um determinado objeto de pesquisa (conferir historicidade à questão racial) e as fontes utilizadas (registros policiais, processos judiciais, jornais, legislação, literatura, testamentos e documentos oficiais) escapam seu vislumbre utópico. Problematizar e estabelecer uma historicidade à raça no Brasil reflete a compreensão e a dimensão que o conhecimento histórico pode proporcionar para Albuquerque.

A pesquisa acadêmica, portanto, pode ser dissecada a partir do texto produzido, mediante seu descortinamento em etapas e procedimentos analíticos.

\section{A performance discursiva: o texto histórico}

O elemento textual, apesar de consistir na última etapa da operação historiográfica, é sintomático pela coalizão entre o lugar social e as práticas de desvio (CERTEAU 2015, p. 89). Dito de forma sequencial, a escrita histórica seria o início do fim de uma pesquisa, é dizer, o contraponto dos procedimentos investigativos, numa verdadeira inversão escriturária (CERTEAU 2015, p. 90). Mas, não é só isso. $O$ ato de escrever história se consolida pelo discurso, não necessariamente reflexo da pesquisa. Por isso, mais uma vez, o historiador exerce papel fundamental na operação historiográfica porque irá concretizar suas práticas metódicas e confirmar seu lugar social, produzindo um discurso histórico (CERTEAU 2015, p. 101). Em outras palavras, o texto histórico, pelo seu conteúdo narrativo, acaba por se aproximar da literatura, mas, ao mesmo tempo, se diferencia desta porque essa representação se dá em meio ao seu ambiente social e em seus aspectos práticos (VOIGT 2014, p. 318).

Assim, a narração pode ser vislumbrada como uma construção, e como toda obra pressupõe inclusões e exclusões. A lógica que transparece nesse processo, portanto, é de responsabilidade do historiador. O caráter inovador de Certeau é dissecar o discurso realizado pelo historiador, tornando-o mensurável e, portanto, controlável. Aqui, o caráter "cientifico" já exposto na primeira seção deste trabalho se apresenta em sua plenitude.

Certeau define o discurso histórico como uma associação entre narrativa e discurso lógico, de modo que a sucessão temporal arbitrariamente estabelecida pelo historiador é enquadrada dentro de um silogismo (2015, p. 100). Assim, o discurso histórico seria a projeção de um sequenciamento temporal para um encadeamento lógico-silogístico, por meio de um deslizamento metafórico, entendido como "uma passagem de um gênero a outro" (CERTEAU 2015, p. 100). Posso, assim, sistematizar esse procedimento da seguinte forma: 
Figura 1 - A construção desdobrada (primeiro aspecto)

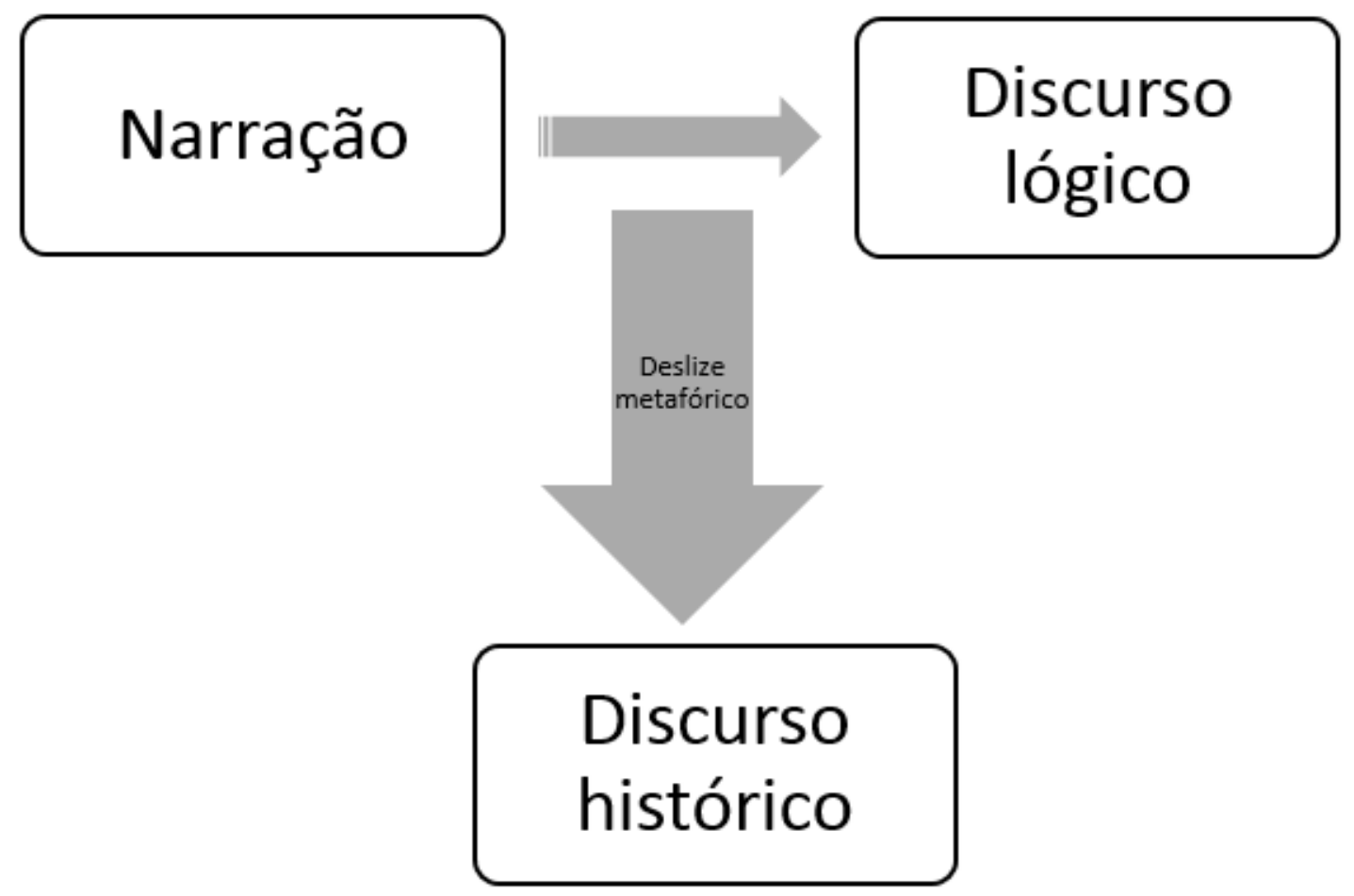

A narrativa, aqui considerada como uma sucessão arbitrária de eventos, é metaforicamente desviada por explicações indutivas ou dedutivas, como 90 um silogismo retórico. o historiador utiliza, portanto, a verossimilhança como instrumento dessa transmudação de discursos. Este ato complexo - resultante do discurso histórico - não se faz sem perda de autoridade, a não ser que, conforme preceitua Certeau (2015, p. 101), seja restabelecida a credibilidade através de uma citação, documental ou por referências de outros historiadores. Ademais, esse diálogo entre o historiador e o leitor se dá por meio de um contrato enunciativo (CERTEAU 2015, p. 103), isto é, o estabelecimento de um vínculo entre as partes, calcado na confiabilidade gerada pelo uso de fontes.

Traçadas essas linhas gerais, creio que já seja possível vislumbrar tais aspectos em trechos da obra ora em estudo.

No primeiro capítulo da obra, há o estabelecimento de uma ordem cronológica e linear, porém desmembrada. A cada etapa sequencial dos episódios, Albuquerque introduz personagens, estabelece inferências e recorre ao argumento de uma autoridade (interpretação prévia de historiadores sobre casos análogos). De forma ilustrativa, , após descrever o contexto social em 1877 e inserir o leitor no universo dos africanos comerciantes que tentavam desembarcar em Salvador, faz remissão ao Conselho de Estado, órgão que analisaria o incidente diplomático envolvendo esses súditos de cor preta: "o desfecho da empreitada dos comerciantes retornados estava à mercê das considerações desses estadistas do Império. Dito isso, pode-se deduzir que o parecer do Conselho em relação à presença dos dezesseis africanos seria, como de fato foi, decisivo" (ALBUQUERQUE 2009, p. 66). 
Nesse momento, a historiadora estanca o desenrolar dos acontecimentos e analisa a trajetória de cada um dos integrantes da referida comissão (Visconde de Jequitinhonha, Eusébio de Queiroz e Nabuco de Araújo), demonstrando que o perfil de cada um deles se voltava para discussões sobre o fim do tráfico e da escravidão. Em seguida, de modo a ratificar seu recorte documental voltado para a forma que tais integrantes do referido órgão imperial iriam decidir o caso concreto, a autora se vale das análises da historiadora Célia Marinho (1994) sobre a diversidade discursiva abolicionista nos Estados Unidos e no Brasil para reforçar e legitimar seu argumento de que "naquele contexto de crise do escravismo, acentuava-se a imagem de brandura das relações entre senhores e escravos no Brasil, na qual não se admitiam restrições construídas sob critérios raciais" (ALBUQUERQUE 2009, p. 73).

Toda essa construção narrativa conduz o leitor a se convencer de que a decisão do Conselho de Estado seria de impedir o desembarque dos africanos sem utilizar fundamentos raciais. Sendo assim, no já avançado discorrer argumentativo, Albuquerque lança a seguinte assertiva:

[...] [n]essa atmosfera de embates entre considerações diplomáticas, convicções ideológicas, silêncios ditados pela política e interesses comerciais, espero já tê-los convencido de que o destino dos africanos do navio Paraguassú estava traçado antes mesmo de o caso ser analisado pelo parecerista da comissão (ALBUQUERQUE 2009, p. 77).

Entre a narrativa do episódio e as conclusões silogísticas decorrentes da exposição argumentativa, Albuquerque precisou introduzir elementos de coesão, dando confiabilidade às exposições, a exemplo de citações de outros historiadores que já haviam interpretado casos concretos similares. Dessa forma, perante acontecimentos aleatórios, a historiadora fornece uma organização temporal e estabelece uma inteligibilidade, atribuindo-lhes, pois, um significante possível. Dessa operação, nasce o fato histórico (CERTEAU 2015, p. 104).

É por este motivo, pois, que Certeau entende todo esse imbricado procedimento como uma construção desdobrada, porque compreende o discurso histórico como o sincretismo de uma sucessividade temporal como métodos de dedução e indução, permeados de discursos de autoridade, de forma a alçar um simples evento à categoria de fato histórico.

Para Chartier (2015, p. 15), essa estrutura mista teria uma tripla função: "convocar o passado que já não está num discurso no presente; mostrar as competências do historiador, dono das fontes; e convencer o leitor". 
Figura 2 - A construção desdobrada completa

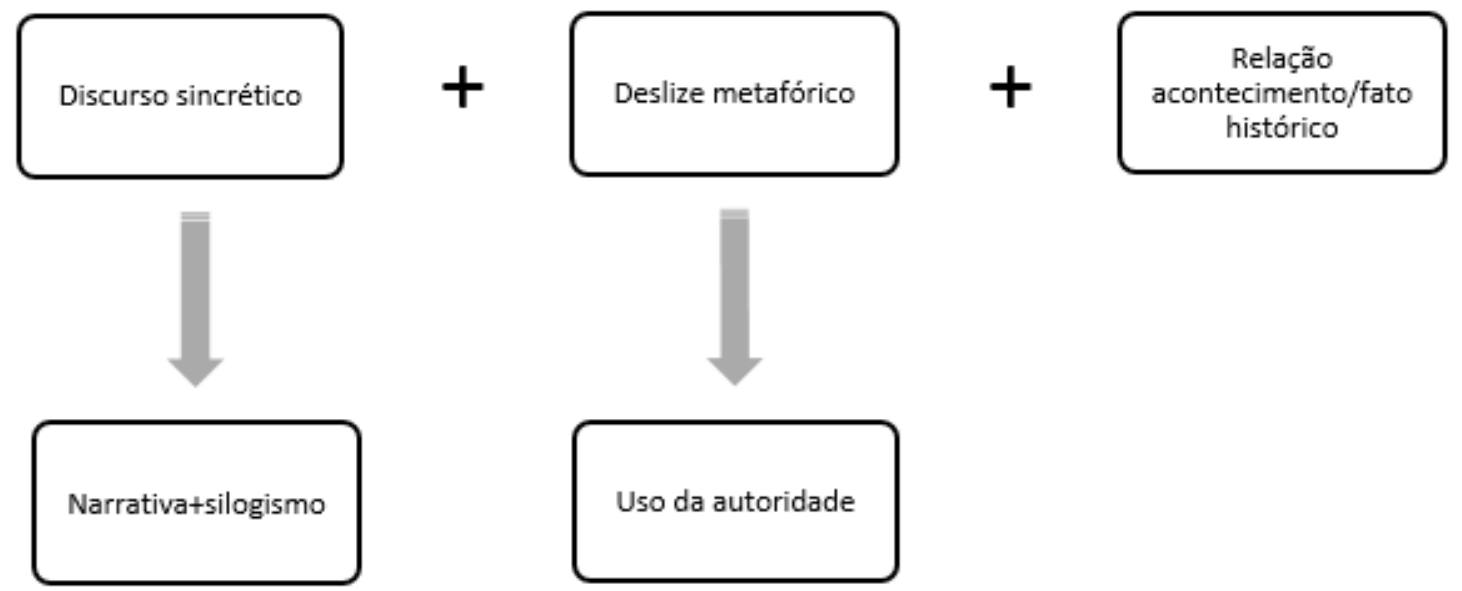

Aplicando esta técnica, verifico que em várias passagens do primeiro capítulo do livro $O$ jogo da dissimulação os documentos não dão conta de explicar o episódio narrado (não há notícias do interrogatório dos africanos, não se sabe o que eles estavam trazendo consigo, inexiste informação do tempo de duração do evento), levando a historiadora a deduzir, pelo contexto social do período (1877), que se tratavam de comerciantes com fluência em inglês e português e que não eram objeto de reescravização. ${ }^{14}$ Como reforço argumentativo e de credibilidade, utiliza não só fontes oficiais e processos judiciais sobre situações semelhantes, como também interpretações de outra 92 historiadora, Manuela Carneiro da Cunha (1986) que já havia analisado o universo comercial e cultural entre Lagos, na África, e Salvador, no Brasil. Por fim, diante de um simples evento (um caso judicial envolvendo a tentativa de desembarque de africanos), a historiadora Wlamyra Albuquerque imprime um sentido, sob o viés de sua hipótese fulcral (a racialização das relações sociais), e, assim, eleva-o ao estatuto de fato histórico por se tornar aspecto que justifica o suporte hipotético (CERTEAU 2015, p. 104) anteriormente lançado: a omissão deliberada do Império em não explicitar que critérios raciais pautavam as decisões do Estado brasileiro.

Dentro desses aspectos discursivos apresentados por Certeau, a questão do deslize metafórico parece exigir também ao historiador um esforço em tornar inteligível a narrativa. Essa hipótese remeteria à necessidade de manuseio de recursos estilísticos como meio hábil de tornar mais próximo e íntimo o diálogo entre o interlocutor e o leitor.

Nesse contexto, a obra em destaque contém uma narrativa clara, acessível, inclusive com tom cinematográfico que convida o leitor a se enveredar nos meandros discursivos sem aperceber tratar-se de um texto acadêmico. Por essa razão, a historiadora esclarece que, embora não intencional, esta habilidade

${ }^{14}$ As possíveis lacunas documentais não impedem o caráter construtivo do historiador. Nesse sentido, conferir a noção de trama em Veyne (1971). 
textual deriva de uma estética inaugurada pelo historiador João José Reis, ${ }^{15}$ que se vale da concepção de que a produção historiográfica é, antes de qualquer questão teórico-metodológica, um contar estórias:

[...] o grupo de escravidão é muito marcado pela narrativa de João Reis. A questão do texto compreensível, a escrita fluida, que pudesse ser lida pelo público em geral. Isso tem muito de um discurso literário, da disposição em escrever uma literatura histórica que facilitasse o acesso do leitor aos seus argumentos. [...] Nessa narrativa sempre há sugestão de literatura, menção de casos, como uma história possível de ler num bar (ALBUQUERQUE, 2016).

A título de exemplo, elenco trecho em que Albuquerque remonta o episódio cunhado de "o massacre do Taboão":

[...] [à]s nove horas da manhã do dia 15 de junho de 1889, era indisfarçável a tensão na cidade. Nosso informante havia pouco saíra de casa com a firme intenção de convencer os três filhos a retornar o mais cedo possível. Ele queria afastá-los da recepção a Silva Jardim, o mais radical propagandista do Partido Republicano que, vindo da Corte, estava prestes a aportar na Bahia. [...] Ao subir a ladeira do Taboão, uma das vidas de ligação entre as partes alta e baixa da cidade, o autor da carta a Rui pôde ouvir uma 'uma gritalhada infernal, gemidos ais e vozes' que diziam: 'mata, mata, mata republicanos, mata Silva Jardim, viva a Monarquia, viva o coronel Santos Marque, viva o partido liberal'. (ALBUQUERQUE 2009, p. 142-143).

Além da característica peculiar da narrativa histórica acima mencionada, Certeau também acrescenta característica singular de descrição do passado: o estabelecimento de uma cronologia ontologicamente não ocorrida (CERTEAU 2015, p. 93-99). O historiador, ao construir um sentido e uma direção aos eventos, estabelece uma temporalização falsificada, mediante o manuseio de personagens como álibi narrativo.

$\mathrm{Na}$ obra em debate, todos os engendramentos dos acontecimentos estão dispostos numa linha de tempo imaginária: é marcando o início da narrativa em 1877, passando pelo ano de 1888 no período do fim da abolição, desaguando em 1897, momento em que analisa os desfiles carnavalescos (ALBUQUERQUE 2009). Conforme anteriormente ventilado, a linha mestra que conduz a narrativa, de natureza linear, é permeada pelo exercício de introdução de personagens como instrumento indutor de raciocínio, mas sempre tendo como elemento norteador um eixo central (que seria uma linha de tempo imaginária). Logo, tanto o sentido como a direção da narrativa é conduzida pela historiadora.

O discurso histórico, portanto, apesar de perfomativo, não é um ato arbitrário. Reconhecer a natureza literária da narrativa não impede que esta seja controlada. Os postulados elencados por Certeau em relação à escrita permitem que tal tarefa seja exequível. 


\section{Considerações finais}

O historiador, ao produzir um discurso expresso em texto, se transforma num exorcista e, também, num visionário: exerce um sepultamento dos mortos, reintroduzindo-os ao presente, de modo a restabelecer um diálogo provocativo e supostamente perdido entre o atual contexto social e o passado (CERTEAU 2015, p. 109).

A trajetória de Albuquerque é composta desta complexa e entrelaçada articulação de narração do passado e estabelecimento de pontes a futuros possíveis. Sua obra acadêmica não se restringe a um novo olhar para o que aconteceu, mas, também, amplia perspectivas, sem perder o ofício de historiadora. Refletir sobre as questões derivadas da escravidão, historicizar a questão racial e buscar compreender os arranjos sociais na Bahia do final do século XIX instrumentalizam e conferem arcabouço teórico capaz de construir projetos nacionais que mitiguem problemas sociais graves em nosso país. Se Wlamyra Albuquerque, como mulher, negra e historiadora, é demandada a responder anseios sociais, ela não se esconde: pelo contrário, devolve-os não só com problematizações e novas abordagens de estudo sobre o passado, mas, também, com propostas que reverberem sua produção historiográfica.

A título de exemplo, Albuquerque integra comitê para ampliação das ações afirmativas na Universidade pública no âmbito da pós-graduação da Universidade Federal da Bahia para, assim, citando a Portaria no 132/2016, de 27 de setembro de 2016, publicado pelo Gabinete da Reitoria da Universidade Federal da Bahia,

94 permitir "à universidade expressar melhor a diversidade étnica, racial, de gênero e de portadores de deficiência existente em nossa sociedade". Trata-se de mais uma contribuição no fazer historiográfico que ultrapassa o elemento textual, mas não perde a essência do discurso histórico.

\section{Referências bibliográficas}

ALBUQUERQUE, Wlamyra R. de. O jogo da Dissimulação: abolição e cidadania negra no Brasil. São Paulo: Companhia das Letras, 2009.

ALBUQUERQUE, Wlamyra R. de. Réplica - O jogo da dissimulação: abolição e cidadania negra no Brasil. Perseu - História, Memória e Política, ano 1, n. 7, p. 288-297, 2011.

ALBUQUERQUE, Wlamyra R. de. Depoimento. Entrevista concedida a Rômulo Gonçalves Bittencourt. Salvador, 7 de out. 2016.

ALBUQUERQUE JR., Durval Muniz. O Tecelão dos Tempos. O historiador como artesão das temporalidades. In: NEGRO, Antônio; SOUZA, Evergton S.; BELLINI, Lígia. Tecendo Histórias. Espaço, política e identidade. Salvador: EDUFBA, 2009a, p. 14-24.

ALBUQUERQUE JR., Durval Muniz. Domingos Sodré, um sacerdote africano: escravidão, liberdade e candomblé na Bahia do século XIX, de João José Reis. Revista Brasileira de História, v. 29, n. 57, p. 211-217, 2009b. 
AZEVEDO, Célia Maria Marinho de. Abolicionismo e memória das relações sociais.

Estudos Afro-Asiáticos, v. 26, p. 5-19, 1994.

BRASIL. Portaria no 132/2016, de 27 de setembro de 2016. Elaboração de proposta de política de Ações Afirmativas para a Pós-Graduação da UFBA. Gabinete da Reitoria da Universidade Federal da Bahia. Palácio da Reitoria, Salvador, 27 de setembro de 2016. Disponível em: https://www.ufba.br/noticias/ reitoria-institui-comiss $\% \mathrm{C} 3 \% \mathrm{~A} 30$-para-discutir-a\%C3\%A7\%C3\%B5esafirmativas-para-p\%C3\%B3s-gradua\%C3\%A7\%C3\%A3o. Acesso em: 19 de outubro de 2016.

BRITO, Ênio José da Costa. O jogo da dissimulação: Abolição e cidadania negra no Brasil, de Wlamyra R. de Albuquerque. Rever - Revista de Estudos da Religião, v. 11, n. 1, p. 209-215, 2011.

COWLING, Camillia. O jogo da dissimulação: Abolição e cidadania negra no Brasil, de Wlamyra R. de Albuquerque. Revista Mundos do Trabalho, v. 3, n. 5, p. 327-329, 2011.

CERTEAU, Michel de. A escrita da história. 3. ed. Rio de Janeiro: Forense, 2015.

CHARTIER, Roger. A história ou a leitura do tempo. 2. ed. Belo Horizonte: Autêntica, 2015.

CUNHA, Manuela Carneiro da. Antropologia do Brasil: mito, história e etinicidade. São Paulo: Brasiliense, 1986.

DOMINGUES, Petrônio. A cidadania Negra. O jogo da dissimulação: Abolição e cidadania negra no Brasil, de Wlamyra R. de Albuquerque. Projeto História, n. 42, p. 421-437, 2011.

FICO, Carlos; POLITO, Ronald. A história no Brasil (1980-1989). Elementos para uma avaliação historiográfica. Ouro Preto: Ed. UFOP, 1992.

KRAAY, Henrdik. Algazarra nas ruas: comemorações da independência na Bahia (1889-1923), de Wlamyra R. de Albuquerque. História Social, n. 8/9, p. 255-259, 2001/2002.

LIMA, Henrique Espada. O jogo da dissimulação: Abolição e cidadania negra no Brasil, de Wlamyra R. de Albuquerque. Perseu - História, Memória e Política, v. 4, p. 247-253, 2009.

GOMES, Tiago de Melo. Dissimulação e outros jogos. Tempo - Revista do Departamento de História da UFF, v. 15, p. 239-244, 2010.

GUIMARÃES, Antônio Sérgio Alfredo. Raça, cor da pele e etnia. Cadernos de campo, n. 20, p. 265-271, 2011.

OHARA, João Rodolfo Munhoz. A história como heterologia: do conceito de História em Michel de Certeau. Dissertação (Mestrado em História) Departamento de História, Universidade Estadual de Londrina, Londrina, 2013. 
ORELLANA, Rodrigo Castro. Michel De Certeau: História e ficção. Princípios Revista de Filosofia, v. 19, n. 31, p. 5-27, 2012.

PEREIRA, Ana Carolina Barbosa. Que objetividade para a ciência da história? O Índio Brasileiro e a Revolução Francesa à luz da teoria da história, de Rüsen a Hayden White. Dissertação (Mestrado em História) Departamento de História, Universidade de Brasília, Brasília, 2007.

RÜSEN, Jörn. Razão histórica. Teorias da história: os fundamentos da ciência histórica. Brasília: Editora da UnB, 2001.

SCHWARTZ, Stuart B. Escravos, Roceiros e Rebeldes. Bauru: Edusc, 2001.

SOUSA, Francisco das Chagas de Loiola. Diálogos com Michel de Certeau sobre pesquisa nas ciências humanas. Revista Crítica Histórica, ano 2, n. 3, p. 181-194, 2011.

VOIGT, A. F. História e Representação: a abordagem de Jacques Rancière. Revista de Teoria da História, v. 11, p. 308-336, 2014. 